\title{
A potential role for zinc transporter 7 in testosterone synthesis in mouse Leydig tumor cells
}

\author{
QINGQING CHU ${ }^{1}$, ZHI-HONG CHI ${ }^{1}$, XIULI ZHANG ${ }^{2}$, DAN LIANG $^{3}$, XUEMEI WANG ${ }^{4}$, \\ YUE ZHAO $^{1}$, LI ZHANG $^{4}$ and PING ZHANG ${ }^{5}$ \\ ${ }^{1}$ Department of Pathophysiology, China Medical University, Shenyang, Liaoning; ${ }^{2}$ Department of Nephrology, \\ Benxi Center Hospital, China Medical University, Benxi, Liaoning; ${ }^{3}$ Troops of 95935 Unit, Harbin, Heilongjiang; \\ ${ }^{4}$ School of Stomatology of China Medical University, Shenyang, Liaoning; ${ }^{5}$ Department of Histology \\ and Embryology, Liaoning Medical College, Jinzhou, Liaoning, P.R. China
}

Received April 21, 2015; Accepted April 14, 2016

DOI: $10.3892 /$ ijmm.2016.2576

\begin{abstract}
Previous studies have demonstrated that zinc ( $\mathrm{Zn})$ is an essential trace element which is involved in male reproduction. The zinc transporter (ZnT) family, SLC30a, is involved in the maintenance of $\mathrm{Zn}$ homeostasis and in mediating intracellular signaling events; however, relatively little is known regarding the effect of ZnTs on testosterone synthesis. Thus, in the present study, we aimed to determine the effect of $\mathrm{Zn}$ transporter 7 (ZnT7) on testosterone synthesis in male CD-1 mice and mouse Leydig cells. The findings of the present study revealed that the concentrations of $\mathrm{Zn}$ in the testes and Leydig cells were significantly lower in mice fed a $\mathrm{Zn}$-deficient diet compared with the control mice fed a $\mathrm{Zn}$-adequate diet. In addition, ZnT7 was principally expressed and colocalized with steroidogenic acute regulatory protein (StAR) in the Leydig cells of male CD-1 mice. ZnT7 expression was downregulated in the mice fed a Zn-deficient diet, which led to decreases in the expression of the enzymes involved in testosterone synthesis namely cholesterol side-chain cleavage enzyme (P450scc) and
\end{abstract}

Correspondence to: Professor Zhi-Hong Chi, Department of Pathophysiology, China Medical University, 77 Puhe Road, Shenbei New Area, Shenyang, Liaoning 110001, P.R. China

E-mail: chizhihong2015@126.com

Dr Xiuli Zhang, Department of Nephrology, Benxi Center Hospital, China Medical University, 29 Victory Road, Benxi, Liaoning 117000, P.R. China

E-mail: zhang2013_11@163.com

Abbreviations: MLTC-1 cells, mouse Leydig tumor cell line; FITC, fluorescein isothiocyanate; TPEN, N,N,N',N'-tetrakis(2-pyridylmethyl) ethylenediamine; PBS, phosphate-buffered saline; ZnT, zinc transporter; LH, luteinizing hormone; FSH, follicle-stimulating hormone; 3 $\beta$-HSD, 3- $\beta$-hydroxysteroid dehydrogenase; P450scc, cholesterol side-chain cleavage enzyme; StAR, steroidogenic acute regulatory protein; CLSM, confocal laser scanning microscope; AAS, atomic absorption spectrophotometry

Key words: Leydig cells, zinc, zinc transporter, siRNA, testosterone synthesis

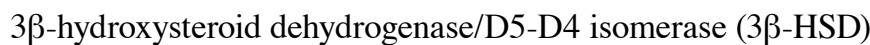
as well as decreased serum testosterone levels. These results suggested that Znt 7 may be involved in testosterone synthesis in the mouse testes. To examine this hypothesis, we used the mouse Leydig tumor cell line (MLTC-1 cell line) in which the ZnT7 gene had been silenced, in order to gauge the impact of changes in $\mathrm{ZnT7}$ expression on testosterone secretion and the enzymes involved in testosterone synthesis. The results demonstrated that $\mathrm{ZnT7}$ gene silencing downregulated the expression of StAR, P450scc and 3 $\beta$-HSD as well as progesterone concentrations in the human chorionic gonadotrophin (hCG)-stimulated MLTC-1 cells. Taken together, these findings reveal that ZnT7 may play an important role in the regulation of testosterone synthesis by modulating steroidogenic enzymes, and may represent a therapeutic target in testosterone deficiency.

\section{Introduction}

Zinc ( $\mathrm{Zn})$ is an essential nutrient and one of the most abundant biological trace metals which is intimately involved in growth and reproduction in males and females $(1,2)$. It is well known that $\mathrm{Zn}$ content is high in the adult testis, and the prostate has a higher concentration of $\mathrm{Zn}$ than any other organ of the body. $\mathrm{Zn}$ plays pivotal roles in testicular development, the maintenance of testicular function and spermatogenesis $(3,4)$. In humans, for example, $\mathrm{Zn}$ is a major constituent of seminal plasma and it is necessary for the formation and maturation of spermatozoa as well as for fertilization $(5,6)$. Epidemiological investigations in humans have demonstrated that the testes have a strict $\mathrm{Zn}$ requirement and a severe $\mathrm{Zn}$ deficiency may lead to low seminal plasma $\mathrm{Zn}$ levels, and the subsequent depletion of testosterone as well as the inhibition of spermatogenesis. This has effects on the fertility of a population, and in one study Zn deficiency was found to be the main cause of a decline in fertility rates $(5,7,8)$. In addition, $\mathrm{Zn}$ deficiency has been demonstrated to cause Leydig cells to appear smaller and show endoplasmic reticulum abnormalities, when examined under an electron microscope (9). Notably, $\mathrm{Zn}$-deficient $(\mathrm{ZnD})$ Leydig cells are capable of taking up cholesterol and neutral lipids, which are the precursors of sex steroids; however, they are incapable of converting them into sex steroids. This has been shown to lead to the arrest of spermatogenesis and 
the impairment of fertilization (10). Indeed, $\mathrm{Zn}$ deficiency has been shown to result in oligospermia, which coincides with poor Leydig cell function and lower testosterone concentrations, and these effects may be reversed with $\mathrm{Zn}$ supplementation $(11,12)$. Thus, $\mathrm{Zn}$, which is known to be an important cation necessary for the normal functioning of the testes and the regulation of fertility, is now attracting increasing attention from researchers.

Previous studies have confirmed that changes in intracellular Zn concentrations exerted marked effects on testicular steroidogenesis processes induced by various physical, chemical and immunological stimuli $(11,13,14)$. Zn homeostasis is regulated by two different Zn-transporter families: the Zrt- and Irt-like proteins (ZIPs; SLC39a) and the Zn transporter (ZnT) proteins (SLC30a). ZIPs facilitate the influx of Zn into the cytosol from the outside of cells or from the lumen of intracellular compartments whereas ZnTs ensure Zn efflux from the cytosol to the outside of cells or to intracellular organelles (15-17). ZnT1 is ubiquitously expressed and the only ZnT known to be involved in $\mathrm{Zn}$ efflux across the plasma membrane in many different cells, thus conferring resistance to $\mathrm{Zn}$ (15). ZnT3 is mainly located in the presynaptic vesicles of neurons and is responsible for the transportation of $\mathrm{Zn}$ into synaptic vesicles involved in nerve transmission $(18,19)$. ZnT5 is thought to transport $\mathrm{Zn}$ into the insulin-containing secretory granules of pancreatic $\beta$-cells (20). ZnT7 is located in the Golgi apparatus and it plays an important role in regulating the efflux of $\mathrm{Zn}$ from the cytosol into the extracellular space or increasing the influx of $\mathrm{Zn}$ into the Golgi network $(14,15,21)$. ZnT8 is predominantly expressed in the insulin-containing granules in pancreatic $\beta$-cells and transports cytoplasmic $\mathrm{Zn}$ ions into the secretory granules for insulin maturation and crystallization prior to secretion $(22,23)$. Previous findings have revealed that coordinated $\mathrm{Zn}$ mobilization by $\mathrm{ZnTs}$ is essential for the maintenance of $\mathrm{Zn}$ homeostasis. Thus, $\mathrm{Zn}$ plays roles in the regulation of critical physiological functions and profoundly affects health positively or negatively, as it is involved in a wide variety of diseases $(17,24)$. The study of $\mathrm{ZnTs}$ is therefore receiving great clinical interest and attention at present (17), although little is known about the functional characteristics of ZnTs, particularly ZnT7, in endocrine tissues such as the mammalian testis.

In the present study, we aimed to examine the role of $\mathrm{ZnT7}$ in testosterone synthesis and to elucidate the underlying mechanisms. Several important transport proteins and enzymes involved in testosterone synthesis were selected for evaluation, including steroidogenic acute regulatory protein (StAR), cholesterol side-chain cleavage enzyme (P450scc) and $3 \beta$-hydroxysteroid dehydrogenase/D5-D4 isomerase (3 $\beta$-HSD). Our results revealed that double immunofluorescence staining between ZnT7 and StAR was mainly observed in the interstitial compartment cells in the mouse testis, and the intensity of staining was weaker in the $\mathrm{ZnD}$ group. Silencing the ZnT7 gene in the mouse Leydig tumor cell line (MLTC-1) cells decreased the levels of StAR, $\mathrm{P} 450$ scc and $3 \beta-\mathrm{HSD}$, and subsequently decreased progesterone synthesis in the MLTC-1 cells. These data suggest that ZnT7 may be involved in steroidogenesis in the mouse testis.

\section{Materials and methods}

Animals. Four-week-old male CD-1 mice, weighing approximately $13 \pm 2 \mathrm{~g}$, were purchased from the Experimental Animal
Center of China Medical University (Shenyang, China). The animals were divided into two groups: 20 animals were fed a ZnD diet (0.85 ppm; egg white-based AIN-76A; Research Diets Inc., New Brunswick, NJ, USA) and provided with deionized water; the other 20 animals were treated with a Zn-adequate (30 ppm) diet and received normal drinking water ad libitum. The mice were housed in cages in a controlled environment $\left(22-25^{\circ} \mathrm{C}\right.$; $50 \%$ humidity; and 12-h/12-h light/ dark cycle). The mice were fed either $\mathrm{ZnD}$ or $\mathrm{Zn}$-adequate diets for 5 weeks. All animal experimental procedures were approved by the Experimental Animal Ethics Committee of China Medical University (Shenyang, China), in accordance with the criteria described in the National Institutes of Health (NIH) Guide for the Care and Use of Laboratory Animals.

Analysis of Zn levels. Following decapitation, the testes of five mice from each group were carefully removed, and the samples were digested with concentrated nitric acid; the digests were diluted to a constant volume with deionized water. The $\mathrm{Zn}$ concentration was then determined from the resultant solution by performing atomic absorption spectrophotometry (AAS) at the Experimental Center of China Medical University (Shenyang, China). The results are expressed as $\mathrm{mg} / \mathrm{g}$ of wet weight (wet wt) and as averages of at least two determinations/sample.

Double immunofluorescence staining. Four animals from the $\mathrm{ZnD}$ group and four from the control group were deeply anesthetized with sodium pentobarbital and perfused with isotonic saline, followed by $4 \%$ paraformaldehyde in $0.1 \mathrm{M}$ phosphatebuffered saline (PBS; pH 7.4). The testes were removed and post-fixed with $4 \%$ paraformaldehyde overnight at $4{ }^{\circ} \mathrm{C}$. Serial paraffin sections $(5 \mu \mathrm{m})$ were prepared, dewaxed in xylene and rehydrated using gradient alcohol solutions. The cryostat sections were then pre-incubated with normal donkey serum (1:20) for $1 \mathrm{~h}$ and incubated overnight at room temperature (RT) with antiZnT7 (polyclonal antibody; HPA018034; Sigma, St. Louis, MO, USA) at 1:100 and anti-StAR (polyclonal antibody; sc-25806; Santa Cruz Biotechnology, Inc., Santa Cruz, CA, USA) at 1:100. Secondary antibodies including fluorescein isothiocyanate (FITC)-conjugated donkey anti-rabbit (FITC-DAR; 711-542-152) IgG and Texas Red-conjugated donkey anti-goat (Texas Red-DAG; 705-007-003) IgG were purchased from Jackson ImmunoResearch Laboratories, Inc. (West Grove, PA, USA). After rinsing with PBS, the sections were incubated for $2 \mathrm{~h}$ with FITC-DAR (1:50) and Texas Red-DAG (1:50) at RT. The sections were mounted and examined under a confocal laser scanning microscope (CLSM; SP2; Leica Microsystems GmbH, Wetzlar, Germany).

Cell culture and treatment with a Zn ion chelating agent. The MLTC-1 cell line was purchased from the Cell Bank, Shanghai Institutes for Biological Sciences, Chinese Academy of Sciences (Shanghai, China) and the cells were maintained in an RPMI-1640 medium (RPMI-1640; Gibco BRL, Grand Island, NY, USA) supplemented with $10 \%$ fetal bovine serum (FBS), $100 \mathrm{IU} / \mathrm{ml}$ of penicillin and $100 \mu \mathrm{g} / \mathrm{ml}$ of streptomycin, at $37^{\circ} \mathrm{C}$ in a $5 \% \mathrm{CO}_{2}$ incubator with humidified 95\% air. To deplete the intracellular $\mathrm{Zn}$ stores, the $\mathrm{Zn}$ chelator $\mathrm{N}, \mathrm{N}, \mathrm{N}$ ',N'-tetrakis(2-pyridylmethyl)ethylenediamine (TPEN; $1 \mu \mathrm{M})$ was added and incubated with the cells for $12 \mathrm{~h}$. 
Assessment of cell viability. Cell viability was measured in 96-well plates by a quantitative colorimetric assay using 3-(4,5-dimethylthiazol-2-yl)-2,5-diphenyltetrazolium bromide (MTT), which is an indicator of mitochondrial activity in living cells. Briefly, at the indicated time after treatment, $10 \mu \mathrm{l}$ MTT (final concentration, $500 \mu \mathrm{g} / \mathrm{ml}$ ) was added to the medium and the cells were incubated at $37^{\circ} \mathrm{C}$ for $3 \mathrm{~h}$. The MTT solution was removed and $100 \mu \mathrm{l}$ dimethyl sulfoxide (DMSO) was added for $15 \mathrm{~min}$ in order to dissolve the resulting colored formazan crystals. The absorbance at $540 \mathrm{~nm}$ for each sample aliquot was measured using a Sunrise RC microplate reader (Tecan Group, Ltd., Männedorf, Switzerland). Cell viability was expressed as the ratio of the signal obtained from the treated cultures to the control.

Transient transfection with mZnT7 (NM_023214) small interfering (si)RNA (Stealth RNAi). The cells were plated in 6-well plates at a density of $2 \times 10^{5}$ cells/well in $2 \mathrm{ml}$ RPMI-1640. ZnT7 siRNA (Stealth RNAi) was prepared by Invitrogen Life Technologies (Carlsbad, CA, USA). The siRNA sequence targeting a specific sequence in ZnT7 mRNA used was 5'-GCCAUAGUCACGAAGCCAATT-3'. The scrambled siRNA sequence used was 5'-UUGGCUUCGUGACUAUGG CTT-3'. The target sequences of ZnT7 siRNA and control ZnT7 siRNA were aligned against the GenBank database using the Basic Local Alignment Search Tool (http://blast.ncbi.nlm.nih. gov/Blast.cgi). Transient transfections were performed according to the manufacturer's instructions using Lipofectamine ${ }^{\circledR} 2000$ (Invitrogen Life Technologies) in order to silence the expression of ZnT7. All experiments were performed in 6-well plates, with the cells plated to reach $50-60 \%$ confluence on the day of transfection. The cells were incubated in growth medium with $10 \%$ FBS for $24 \mathrm{~h}$ after transfection. The knockdown of ZnT7 was evaluated using western blot analysis.

Hormone assays. Blood was collected by cardiac puncture with a heparinized syringe and serum was immediately collected by centrifugation $\left(4,000 \mathrm{rpm}\right.$ at $\left.4^{\circ} \mathrm{C}\right)$ and stored at $-20^{\circ} \mathrm{C}$ for further analysis. The serum sample concentrations of luteinizing hormone ( $\mathrm{LH})$ and testosterone were measured using an enzyme-linked immunosorbent assay as described in the instructions provided with the assay kits (DRG Instruments $\mathrm{GmbH}$, Marburg, Germany). For the cell experiments, following transfection or treatment with TPEN (Sigma), the supernatants were collected $2 \mathrm{~h}$ after human chorionic gonadotrophin (hCG) stimulation. The total progesterone levels were detected in the culture medium using the above-mentioned method.

Western blot analysis. The decapsulated testes were placed in a 15-ml conical tube containing 2-10 ml DMEM/Ham's F12 (DMEM/F12) and subjected to rocking horizontal incubation at room temperature at $250 \mathrm{rpm}$ for $40 \mathrm{~min}$. Shortly after resting for $1 \mathrm{~min}$, suspended cells in the upper fraction were separated from the bottom fraction. Upper fraction cells primarily consisting of Leydig cells were centrifuged at $200 \mathrm{x} g$ for $5 \mathrm{~min}$ and subjected to western blot analysis. The Leydig cells isolated from the testes of 11 mice were minced into small pieces and homogenized in a chilled lysis buffer $(150 \mathrm{mM}$ of $\mathrm{NaCl}, 50 \mathrm{mM}$ of Tris- $\mathrm{HCl}$, $1 \%$ Nonidet P-40, $0.25 \%$ sodium deoxycholate, $0.1 \%$ SDS, $1 \mathrm{mM}$ of PMSF, $10 \mathrm{mg} / \mathrm{ml}$ of leupeptin, $1 \mathrm{mM}$ of $\mathrm{Na}_{3} \mathrm{VO}_{4}$, and $1 \mathrm{mM}$ of $\mathrm{NaF}$ ) overnight at $4^{\circ} \mathrm{C}$. The MLTC- 1 cell pellets were lysed in a chilled lysis buffer for an hour at $4^{\circ} \mathrm{C}$. The lysates were collected, centrifuged at 12,000 rpm for $30 \mathrm{~min}$, and quantified for total protein using a UV 1700 PharmaSpec ultraviolet spectrophotometer (Shimadzu, Kyoto, Japan). The supernatant was removed, portioned into aliquots, and then stored at $-80^{\circ} \mathrm{C}$.

Fifty micrograms of total protein from each sample were subjected to SDS-PAGE using 10\% gradient Tris/glycine gels. The proteins were then transferred to polyvinylidene difluoride (PVDF) membranes (Millipore Corp., Temecula, CA, USA). After blocking with 5\% fat-free milk for $1 \mathrm{~h}$, the blots were incubated with the following primary antibodies: anti-ZnT7 (1:1,000; HPA018034; Sigma), anti-StAR (1:1,000; sc-25806; Santa Cruz Biotechnology, Inc.), anti-P450SCC (1:1,000; ABS235; Millipore Corp.), anti-3 $\beta$-HSD (1:1,000; sc-28206; Santa Cruz Biotechnology, Inc.), and anti-GAPDH (1:10,000; G8795; KangChen Biotech, Shanghai, China) at $4^{\circ} \mathrm{C}$ overnight. The membranes were incubated with an horseradish peroxide (HRP)conjugated goat anti-rabbit IgG (H + L; 170-6515; Biocompare, San Francisco, CA, USA), HRP-conjugated goat anti-mouse IgG ( $\mathrm{H}+\mathrm{L}$; 170-6515; Biocompare), and HRP-conjugated rabbit anti-goat $\operatorname{IgG}(\mathrm{H}+\mathrm{L}$; ab6721; Abcam, Cambridge, UK) (1:5,000) for $2 \mathrm{~h}$ at room temperature. Immunoreactive bands were visualized using a SuperSignal West Pico Chemiluminescent substrate (Pierce Biotechnology, Rockford, IL, USA) with a ChemDoc XRS imaging system and Quantity One software (Bio-Rad, Hercules, CA, USA).

Statistical analysis. Continuous variables are expressed as the means \pm standard error of the mean (SEM). One-way analysis of variance (ANOVA) was used to analyze the data. Tukey's multiple comparison test was used. $\mathrm{P}<0.05$ was considered to indicate a statistically significant difference.

\section{Results}

Colocalization of ZnT7 and StAR in the Leydig cells of mouse testes. To examine the association between $\mathrm{ZnT} 7$ and testosterone synthesis as well as testosterone-related factors in Leydig cells, we first examined whether ZnT7 proteins are expressed in the Leydig cells from the mouse testis. Testosterone is essential for spermatogenesis, fertility and the maintenance of the male phenotype (25). StAR protein and testosterone biosynthetic enzymes play critical roles in the synthesis of testosterone in Leydig cells (26-28). Double immunofluorescence staining for ZnT7 and StAR was performed to analyze the distribution and localization of both proteins in the mouse testis. Using a CLSM, ZnT7-positive cells were found to be distributed in the interstitial compartment and the seminiferous tubules of the mouse testis. The intensity of ZnT7 staining in the interstitial compartment cells was stronger than that in the seminiferous tubule; StAR staining was exclusively located in the interstitial compartment cells (Fig. 1). The merged images illustrated that ZnT7 was colocalized with StAR in the interstitial compartment cells in the mouse testis (Fig. 1). Furthermore, we found that the staining for both ZnT7 and StAR was weaker in the Leydig cells from the mice in the $\mathrm{ZnD}$ group compared with the control group. These results demonstrated that ZnT7 was expressed in the interstitial compartment cells of the mouse testes and may be involved in steroidogenesis. 

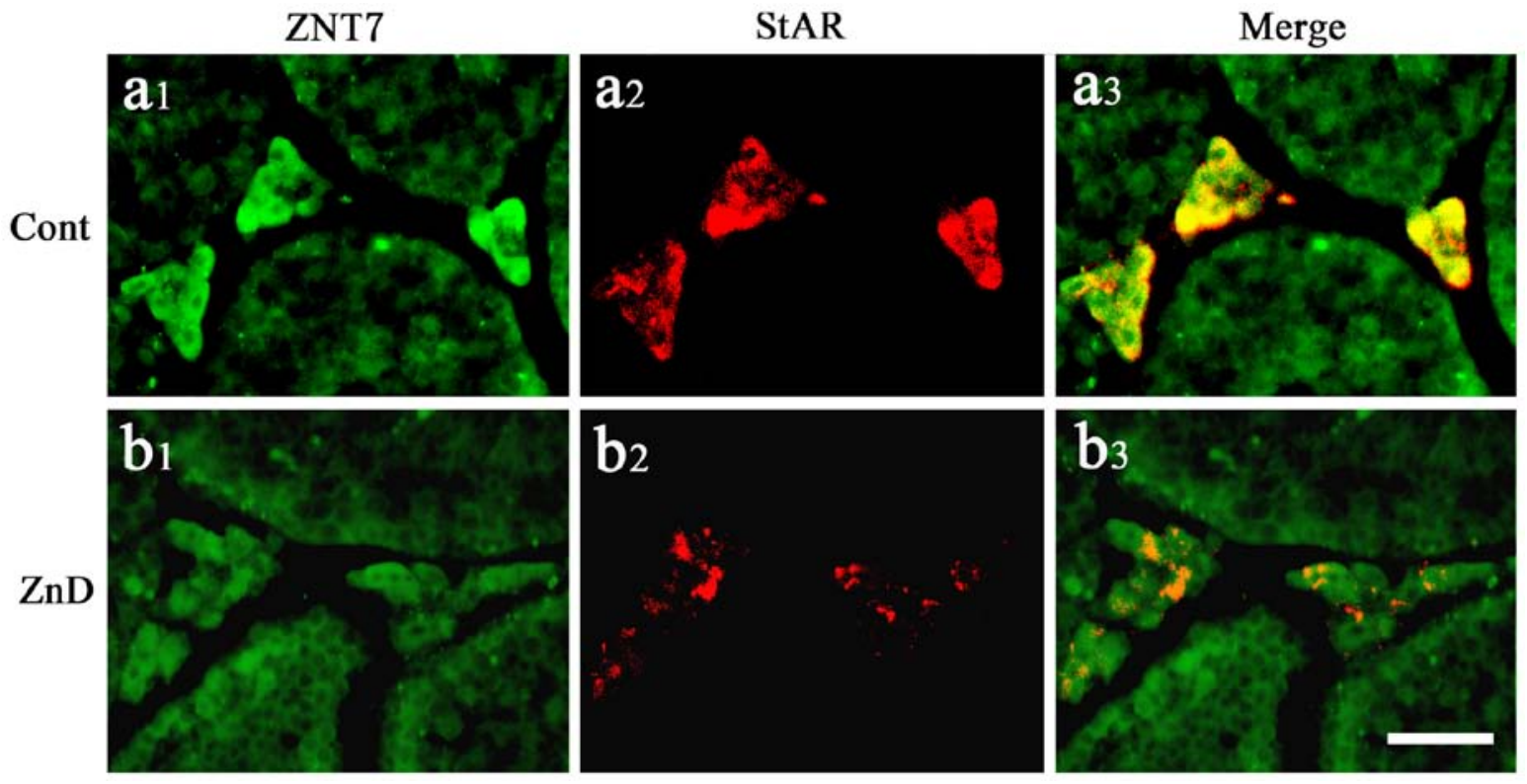

Figure 1. Colocalization of zinc transporter 7 (ZnT7) and steroidogenic acute regulatory protein (StAR) in the Leydig cells from mouse testes. ZnT7-positive cells and StAR-positive cells were found to be distributed in the interstitial compartment. Merged images show that ZnT7 was colocalized with StAR in the interstitial compartment of the mouse testis. Compared with the control (Cont) group, the stain intensity of both ZnT7 and StAR were weaker in the Leydig cells from the $\mathrm{Zn}$ deficient $(\mathrm{ZnD})$ group. Scale bar, $50 \mu \mathrm{m}$.
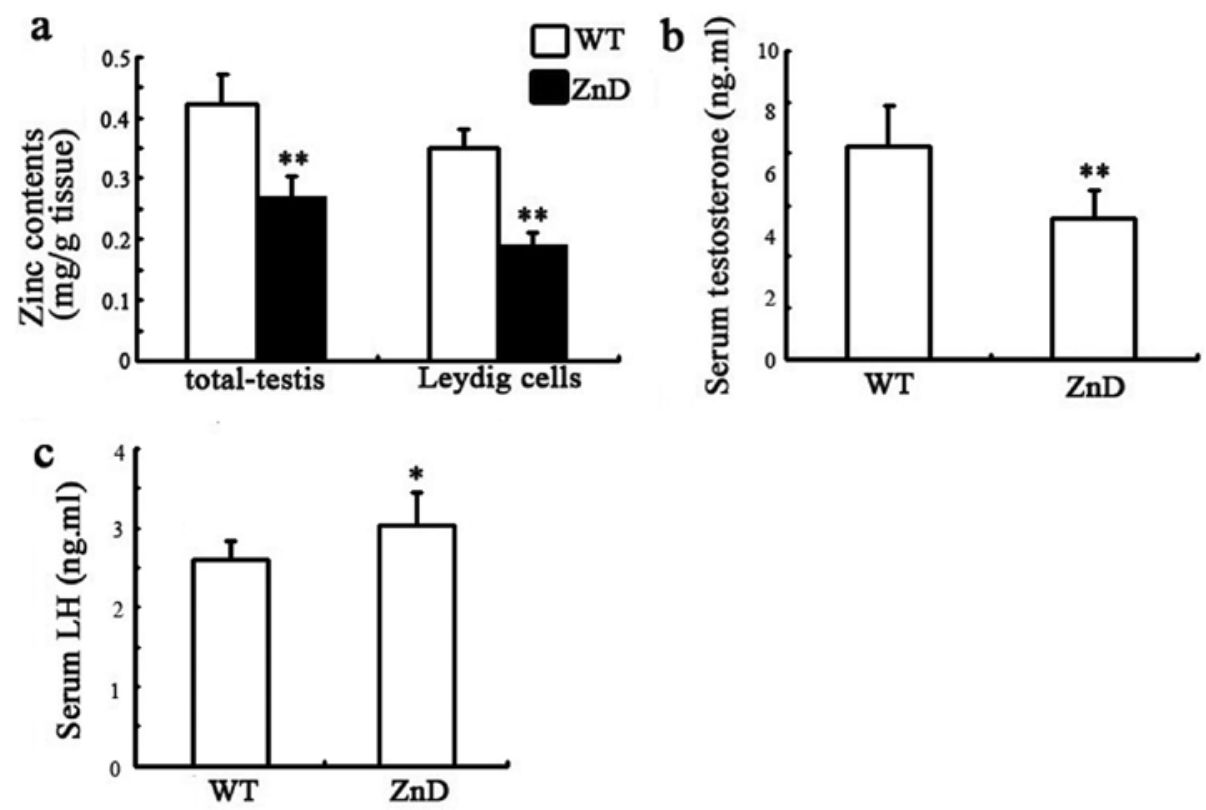

Figure 2. Effects of $\mathrm{Zn}$ deficiency on $\mathrm{Zn}$ concentrations in the mouse testes and serum levels of luteinizing hormone (LH) and testosterone. (a) Atomic absorption spectroscopy was used to examine the $\mathrm{Zn}$ ion concentration in the total testis and isolated Leydig cells. The $\mathrm{Zn}$ ion concentrations in the testis and isolated Leydig cells were significantly decreased in the $\mathrm{Zn}$ deficient $(\mathrm{ZnD})$ group compared with the control group. (b and c) The serum levels of testosterone and LH were tested. All experiments were repeated three times, and the results are presented as the means \pm standard error of the mean. ${ }^{*} \mathrm{P}<0.05$, vs. control; ${ }^{* *} \mathrm{P}<0.01$, vs. control. WT, mice fed a zinc-adequate diet.

Effects of $\mathrm{Zn}$ deficiency on $\mathrm{Zn}$ concentrations in mouse testes and serum levels of $L H$ and testosterone. In an in vivo experiment, AAS was used to determine the concentration of $\mathrm{Zn}$ ions in the mouse testis. As compared with the control group, both the $\mathrm{Zn}$ concentrations in the testis (total) and the isolated Leydig cells were significantly decreased in the $\mathrm{ZnD}$ group (Fig. 2a). In addition, we also evaluated the circulating LH content and testosterone levels in the serum. As expected, the mice fed a $\mathrm{ZnD}$ diet had significantly lower serum concentrations of testosterone and higher serum concentrations of $\mathrm{LH}$ than in the control group (Fig. 2b and c).

Effects of $\mathrm{Zn}$ deficiency on the protein expression of ZnT7 and testosterone-related factors in the mouse Leydig cells. To assess the effect of $\mathrm{Zn}$ deficiency on the expression of ZnT7 and testosterone-related factors in mouse Leydig cells, several 

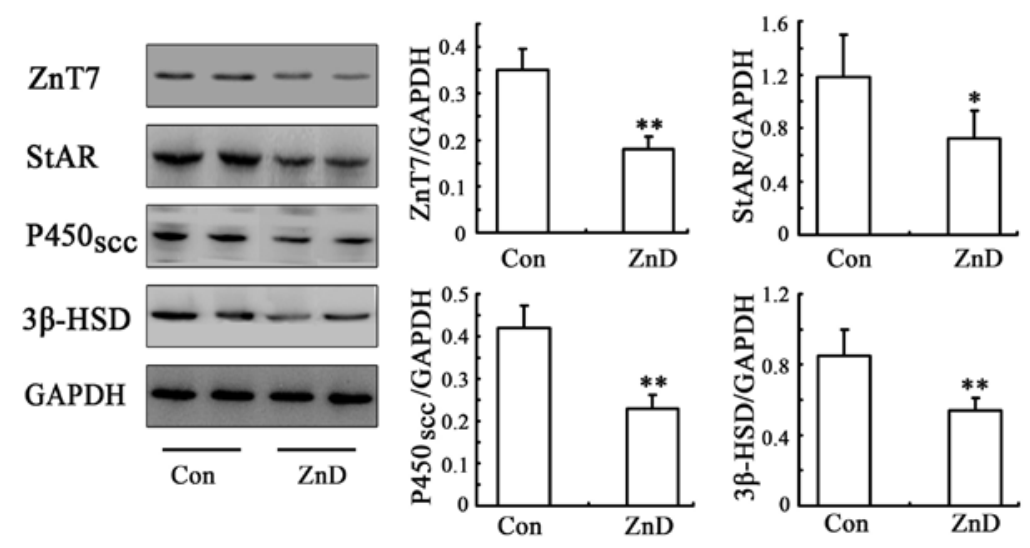

Figure 3. Effects of Zn deficiency on the protein expression of Zn transporter 7 (ZnT7) and testosterone-related factors in mouse Leydig cells. The protein expression of ZnT7, steroidogenic acute regulatory protein (StAR), cholesterol side-chain cleavage enzyme (P450scc) and 3- $\beta$-hydroxysteroid dehydrogenase $(3 \beta-H S D)$ was detected by western blot analysis. Each value represents the means \pm standard error of the mean. All experiments were performed three times with virtually identical results. GAPDH was used as the loading control. ${ }^{*} \mathrm{P}<0.05$ vs. control group; ${ }^{* *} \mathrm{P}<0.01$ vs. control group.

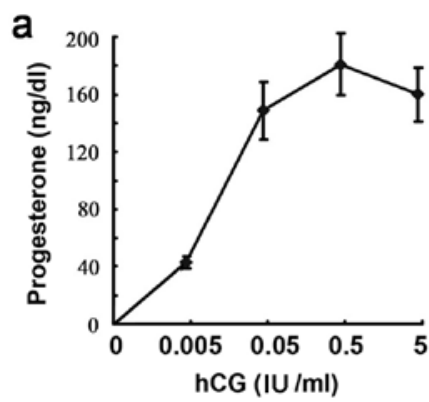

d

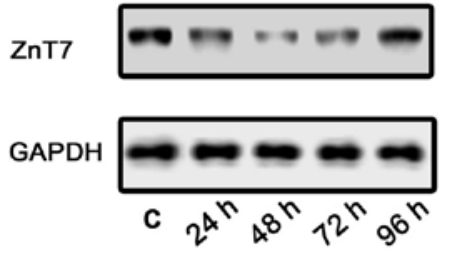

b

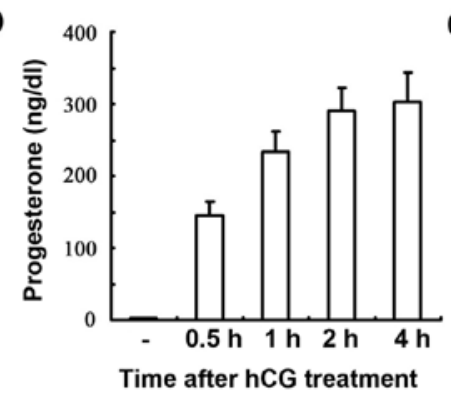

e

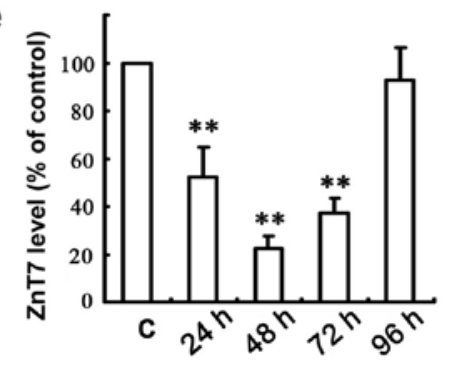

C

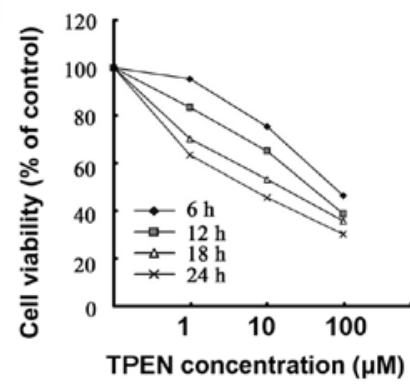

Figure 4. Evaluation of RNAi-mediated knockdown of Zn transporter 7 (ZnT7) and cell viability in MLTC-1 cells. (a) MLTC-1 cells were treated with 0-5 IU/ml human chorionic gonadotrophin (hCG) and progesterone levels in the media were measured after $0.5 \mathrm{~h}$. (b) MLTC-1 cells were stimulated with $5 \mathrm{IU} / \mathrm{ml}$ hCG and progesterone levels in the media were measured at different time-points ( $0-4 \mathrm{~h})$. (c) MLTC-1 cells were exposed to various doses of N,N,N',N'-tetrakis(2pyridylmethyl)ethylenediamine (TPEN) $(0-100 \mu \mathrm{m})$ for $6,12,18$ or $24 \mathrm{~h}$, and cell viability was analyzed by the MTT assay. All experiments were repeated three times, and the results are presented as the means \pm standard error of the mean. (d and e) ZnT7 protein expression was detected by western blot analysis following the transfection of MLTC-1 cells with mZnT7 siRNA for different time periods. Each value represents the means \pm standard error of the mean (n=3). All experiments were performed three times with virtually identical results. GAPDH was used as the loading control. ${ }^{* *} \mathrm{P}<0.01$ vs. control group.

important transport proteins and enzymes involved in testosterone synthesis were selected for evaluation, namely StAR, P450scc and 3 $\beta$-HSD (29-31).P450scc is a hormonally-regulated mitochondrial enzyme which converts insoluble cholesterol to soluble pregnenolone (30). Pregnenolone is then metabolized to androgens by $3 \beta$-HSD $(25,30)$. Notably, Zn deficiency which downregulated $\mathrm{ZnT} 7$ levels also decreased the protein expression of StAR, P450scc and 3 $\beta$-HSD compared with that in the control groups (Fig. 3). Overall, these results suggest that ZnT7 plays an essential role in the reduced testosterone synthesis that occurs in response to $\mathrm{Zn}$ deficiency.

RNAi-mediated knockdown of ZnT7 and Zn deficiency may inhibit hCG-induced testosterone synthesis and downregulate testosterone-related factors in MLTC-1 cells. In the present study, MLTC-1 cells were used as a model cell line and hCG was used to induce steroidogenesis in order to elucidate the mechanism underlying the involvement of ZnT7 in testosterone synthesis. The established MLTC-1 cell line has the capability to synthesize progesterone as the key steroid in response to hCG and to keep to a consistent gonadotropin response before progesterone synthesis compared with the primary Leydig cell line (32). The cells were treated with increasing amounts of hCG for $30 \mathrm{~min}$, and the progesterone levels in the media were measured using a chemiluminescent enzyme immunoassay. The saturating amount of hCG was approximately $0.5 \mathrm{IU} / \mathrm{ml}$ (Fig. 4a). This amount of hCG $(0.5 \mathrm{IU} / \mathrm{ml})$ was used in subsequent experiments. The 

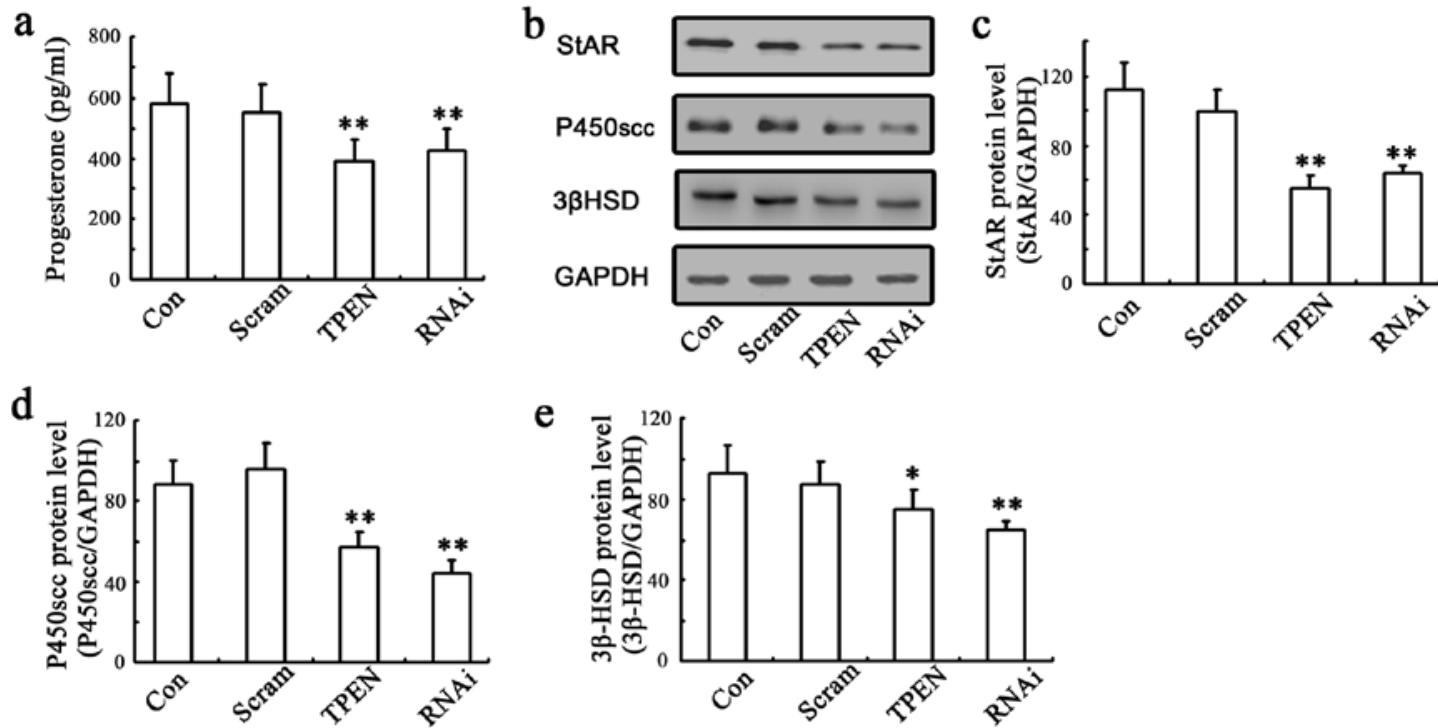

Figure 5. RNA-mediated knockdown of Zn transporter 7 (ZnT7) and Zn deficiency may inhibit steroidogenesis and steroidogenesis-related factors in MLTC-1 cells following human chorionic gonadotrophin (hCG) stimulation. (a) MLTC-1 cells were stimulated with $0.5 \mathrm{IU} / \mathrm{ml}$ of hCG for $2 \mathrm{~h}$ with $1 \mu \mathrm{M} \mathrm{N}, \mathrm{N}, \mathrm{N}, \mathrm{N}^{\prime}-$ tetrakis(2-pyridylmethyl)ethylenediamine (TPEN) or ZnT7-siRNA and progesterone production in the media was measured at 0-4 h. (b-e) Western blot analysis was performed with an antibody against steroidogenic acute regulatory protein (StAR), cholesterol side chain cleavage enzyme (P450scc), and 3 - $\beta$-hydroxysteroid dehydrogenase ( $3 \beta$-HSD). Corresponding protein levels were assessed using densitometry and expressed in relative intensities. All results were obtained from three independent experiments. Values are expressed as the means \pm standard error of the mean. ${ }^{*} \mathrm{P}<0.05$ vs. control group; ${ }^{* *} \mathrm{P}<0.01$ vs. control group. Scram, scrambled siRNA; Cont, control.

hCG-induced steroid production was consistently detectable as early as $0.5 \mathrm{~h}$ post-treatment and reached a steady peak at approximately 2-4 h post-treatment (Fig. 4b). We selected $2 \mathrm{~h}$ as the optimum incubation time for subsequent experiments. To avoid potential toxic effects resulting in cell death in the following experiments, we performed a cell viability assay in order to determine the optimal TPEN concentration and incubation time (Fig. 4c). Accordingly, a concentration of $1 \mu \mathrm{m}$ TPEN and a $12 \mathrm{~h}$ incubation time were selected.

To examine the effects of ZnT7 on testosterone synthesis, we determined whether ZnT7 knockdown was capable of preventing the events of steroidogenesis. Firstly, western blot analysis was performed in order to detect ZnT7 protein expression following the transfection of MLTC-1 cells with mZnT7 siRNA, which revealed that the optimal effect was achieved at $48 \mathrm{~h}$ posttransfection and the inhibition rate of ZnT7 RNAi reached $>80 \%$ (Fig. 4d and e). Subsequently, hCG-stimulated cells were then used to determine whether Zn homeostasis and ZnT7 expression are involved in steroidogenesis in MLTC-1 cells (33-35). The MLTC- 1 cells were treated with $0.5 \mathrm{IU} / \mathrm{ml}$ of hCG for $2 \mathrm{~h}$ with $1 \mu \mathrm{M}$ TPEN or ZnT7 siRNA and progesterone production in the media was measured at $2 \mathrm{~h}$ after hCG treatment. ZnT7 knockdown decreased progesterone production and downregulated the expression of StAR, P450scc and 3 $\beta$-HSD following hCG stimulation of the MLTC-1 cells. In addition, exposure to TPEN decreased progesterone levels and the factors mentioned above (Fig. 5a-e). Taken together, these findings suggest that ZnT7 appears to play a role in steroidogenesis induced by hCG, by modulating the expression of several steroidogenic enzymes.

\section{Discussion}

Previous studies have reported that $\mathrm{Zn}$ plays important roles in the production, storage and secretion of a number of hormones including testosterone $(26,36)$. Studies in animal models as well as clinical studies have demonstrated that hypogonadism is a prominent feature of $\mathrm{Zn}$ deficiency in humans and animals $(37,38)$; however, the underlying mechanisms responsible for these endocrine effects observed in $\mathrm{Zn}$ deficiency remain unclear. The present study has reported a significant decrease in serum testosterone levels and $\mathrm{Zn}$ concentrations in the testis and Leydig cells of mice, which is in line with the findings of previous studies on a number of male mammal species (37-40). In addition, ZnT7 was prinicipally expressed and colocalized with StAR in the Leydig cells of male CD-1 mice. ZnT7 expression was downregulated in the mice fed a $\mathrm{ZnD}(0.85 \mathrm{ppm})$ diet as were the enzymes involved in testosterone synthesis, including P450scc and 3 $\beta$-HSD, as well as testosterone levels. Furthermore, ZnT7 gene silencing downregulated the levels of StAR, P450scc, $3 \beta$-HSD and progesterone in the hCG-stimulated MLTC-1 cells. These results are the first to demonstrate that $\mathrm{Znt} 7$ is involved in testosterone synthesis in the mouse testis and MLTC-1 cells, to the best of our knowledge. The mechanism underlying this process may involve the modulation of the expression levels of testosterone-related factors in MLTC-1 cells.

$\mathrm{Zn}$ is critical for the production, storage and secretion of various enzymes, including a number of $\mathrm{Zn}$-dependent enzymes, that are involved in cellular signaling pathways as well as for the activity of certain transcription factors $(41,42)$. Studies in humans and animal models have determined that severe $\mathrm{Zn}$ deficiency negatively affects male reproduction by inducing testicular atrophy, reducing the functioning of $\mathrm{LH}$ receptor and steroid synthesis, and causing Leydig cell damage as a result of oxidative stress $(9,43)$. In addition, $\mathrm{Zn}$ deficiency may cause the degeneration of Leydig cells involved in the processing of spermatozoa after meiotic division (40). More specifically, ZnD testicular Leydig cells are capable of-taking up cholesterol and 
neutral lipids which are precursors of sex steroids; however, they are unable to convert them into sex steroids. This leads to the arrest of spermatogenesis and the impairment of fertilization $(10,38)$. The present study demonstrated that in male mice, dietary $\mathrm{Zn}$ deficiency significantly reduced the level of testosterone and increased the circulating level of $\mathrm{LH}$, thus indicating that the release and synthesis of LH occurred under conditions of $\mathrm{Zn}$ depletion. These data are in agreement with previous findings obtained by other researchers, who demonstrated that rats exhibited significant decreases in the serum levels of testosterone and progesterone together with increases in serum levels of follicle-stimulating hormone (FSH) and LH $(3,5,44)$. Furthermore, in vitro experiments have demonstrated that decreased levels of progesterone synthesis by Leydig cells as well as the decreased expression of StAR, P450scc and 3 $\beta-H S D$ in the Leydig cells occurred under conditions of $\mathrm{Zn}$ depletion. The results of in vitro and in vivo experiments in the present study have therefore indicated that $\mathrm{Zn}$ deficiency may exert a direct inhibitory effect on testosterone synthesis in Leydig cells. This explains the reduction in testosterone synthesis, which was confirmed by evidence that progesterone production was decreased and the expression of the key steroidogenic enzymes was downregulated in the mice with dietary Zn deficiency.

It is believed that ZnTs are involved in a number of physiological pathways and processes, such as insulin synthesis and secretion in the pancreas, cognitive function, bone development and body adiposity $(37,45)$. The roles of ZnTs in the pathogenesis of disease have received great attention and monitoring cellular $\mathrm{Zn}$ status may have an important impact on disease prevention and treatment $(45,46)$. Several studies have demonstrated that ZnT7 is located in the Golgi apparatus and may participate in the transport of cytoplasmic $\mathrm{Zn}$ into the Golgi apparatus $(21,47)$. ZnT7-deficient rats had lower levels of $\mathrm{Zn}$ in their cells and tissues, a reduced food intake, and poor growth; all of which are clinical manifestations of $\mathrm{Zn}$ deficiency (39). In the present study, double immunofluorescence staining revealed the colocalization of ZnT7 and StAR in the mouse Leydig cells. The silencing of $\mathrm{ZnT} 7$ gene expression demonstrated the impact of changes in ZnT7 expression on testosterone secretion as well as the expression of the enzymes involved in testosterone synthesis in MLTC-1 cells which suggested that $\mathrm{ZnT} 7$ may play a role in the the regulation of steroidogenesis. It is well known that ZnT7 may play a direct role in maintaining $\mathrm{Zn}$ concentrations within the Golgi apparatus, which is a vital organelle for protein synthesis and post-translational modification (48-50). Previous research has demonstrated that the overexpression of $\mathrm{ZnT} 7$ in Chinese hamster ovarian cells led to an accumulation of $\mathrm{Zn}$ in the Golgi apparatus, indicating that ZnT7 may play an important role in delivering $\mathrm{Zn}$ to newly synthesized Zn-requiring enzymes, proteins, or in the storage of $\mathrm{Zn}$ in the Golgi apparatus $(49,51)$. In the present study, we found that the protein expression of StAR, P450scc and 3 $\beta$-HSD were significantly decreased in the ZnT7-silenced MLTC-1 cells, compared with that in the control groups. The changes we observed suggest that ZnT7 may affect testosterone synthesis in MLTC-1 cells by regulating the levels of testosterone-related factors through the metal-responsive element in testosterone synthesis promoters and $\mathrm{Zn}$-requiring proteins or processes, or through the export of $\mathrm{Zn}$ from the Golgi apparatus through $\mathrm{ZnTs}$.
In conclusion, in the present study we present novel evidence regarding the association between $\mathrm{ZnT7}$ and testosterone synthesis through in vivo experiments on the tests of male CD-1 mice and in vitro experiments on MLTC-1 cells. Our results have demonstrated that the expression of ZnT7 as well as StAR, P450scc and 3 $\beta$-HSD was reduced, respectively, in the $\mathrm{ZnD}$ group together with a decreased serum testosterone level. In particular, the silencing of the $\mathrm{ZnT7}$ gene resulted in the reduced expression of StAR, P450scc and 3 $\beta$-HSD as well as in decreased progesterone levels. Given the important role that testosterone synthesis plays in the development and progression of gonadal differentiation, formation and maturation, the identification of ZnT7 as a key regulator of testosterone synthesis represents an important finding. Future studies may confirm ZnT7 as a potentially important target for therapeutic intervention, in an attempt to regulate steroidogenesis in order to limit the decline in fertility observed in patients with Zn deficiency.

\section{Acknowledgements}

The present study was supported by the National Grand Fundamental Research 973 Program of China (no. 2012CB722405), the Natural Science Foundation of China (no. 81170561), and the Liaoning Province Science and Technology Plan Project (nos. 2012408002 and 2013225090).

\section{References}

1. Hidiroglou $\mathrm{M}$ and Knipfel JE: Zinc in mammalian sperm: a review. J Dairy Sci 67: 1147-1156, 1984.

2. Coleman JE: Zinc proteins: enzymes, storage proteins, transcription factors, and replication proteins. Annu Rev Biochem 61: 897-946, 1992.

3. Hartoma TR, Nahoul K and Netter A: Zinc, plasma androgens and male sterility. Lancet 2: 1125-1126, 1977.

4. Aihara K, Nishi Y, Hatano S, Kihara M, Ohta M, Sakoda K, Uozumi T and Usui T: Zinc, copper, manganese, and selenium metabolism in patients with human growth hormone deficiency or acromegaly. J Pediatr Gastroenterol Nutr 4: 610-615, 1985.

5. Bedwal RS and Bahuguna A: Zinc, copper and selenium in reproduction. Experientia 50: 626-640, 1994.

6. El Hendy HA, Yousef MI and Abo El-Naga NI: Effect of dietary zinc deficiency on hematological and biochemical parameters and concentrations of zinc, copper, and iron in growing rats. Toxicology 167: 163-170, 2001.

7. Matossian MK: Fertility decline in Europe, 1875-1913. Was zinc deficiency the cause? Perspect Biol Med 34: 604-616, 1991.

8. Brown KH and Wuehler SE (eds): Zinc and human health: results of recent trials and implications for program interventions and research. Micronutrient Initiative, Ottawa, 2000.

9. Hesketh JE: Effects of dietary zinc deficiency on Leydig cell ultrastructure in the boar. J Comp Pathol 92: 239-247, 1982.

10. Lei KY, Abbasi A and Prasad AS: Function of pituitary-gonadal axis in zinc-deficient rats. Am J Physiol 230: 1730-1732, 1976.

11. Hadwan MH, Almashhedy LA and Alsalman AR: Study of the effects of oral zinc supplementation on peroxynitrite levels, arginase activity and NO synthase activity in seminal plasma of Iraqi asthenospermic patients. Reprod Biol Endocrinol 12: 1, 2014.

12. Abbasi AA, Prasad AS and Rabbani PR: Experimental zinc deficiency in man: effect on spermatogenesis. Trans Assoc Am Physicians 92: 292-302, 1979.

13. Khan MS, Zaman S, Sajjad M, Shoaib M and Gilani G: Assessment of the level of trace element zinc in seminal plasma of males and evaluation of its role in male infertility. Int J Appl Basic Med Res 1: 93-96, 2011.

14. Chasapis CT, Loutsidou AC, Spiliopoulou CA and Stefanidou ME: Zinc and human health: an update. Arch Toxicol 86: 521-534, 2012. 
15. Kambe T, Yamaguchi-Iwai Y, Sasaki R and Nagao M: Overview of mammalian zinc transporters. Cell Mol Life Sci 61: 49-68, 2004.

16. Palmiter RD and Huang L: Efflux and compartmentalization of zinc by members of the SLC30 family of solute carriers. Pflugers Arch 447: 744-751, 2004.

17. Kambe T, Hashimoto A and Fujimoto S: Current understanding of ZIP and ZnT zinc transporters in human health and diseases. Cell Mol Life Sci 71: 3281-3295, 2014.

18. Palmiter RD, Cole TB, Quaife CJ and Findley SD: ZnT-3, a putative transporter of zinc into synaptic vesicles. Proc Natl Acad Sci USA 93: 14934-14939, 1996.

19. Cole TB, Wenzel HJ, Kafer KE, Schwartzkroin PA and Palmiter RD: Elimination of zinc from synaptic vesicles in the intact mouse brain by disruption of the ZnT3 gene. Proc Natl Acad Sci USA 96: 1716-1721, 1999.

20. Kambe T, Narita H, Yamaguchi-Iwai Y, Hirose J, Amano T, Sugiura N, Sasaki R, Mori K, Iwanaga T and Nagao M: Cloning and characterization of a novel mammalian zinc transporter zinc transporter 5, abundantly expressed in pancreatic beta cells. J Biol Chem 277: 19049-19055, 2002.

21. Kirschke CP and Huang L: ZnT7, a novel mammalian zinc transporter, accumulates zinc in the Golgi apparatus. J Biol Chem 278: 4096-4102, 2003.

22. Lemaire K, Chimienti F and Schuit F: Zinc transporters and their role in the pancreatic $\beta$-cell. J Diabetes Investig 3: 202-211, 2012.

23. Chimienti F, Devergnas S, Favier A and Seve M: Identification and cloning of a beta-cell-specific zinc transporter, ZnT-8, localized into insulin secretory granules. Diabetes 53: 2330-2337, 2004.

24. Kambe T, Weaver BP and Andrews GK: The genetics of essential metal homeostasis during development. Genesis 46: 214-228, 2008.

25. Jiang MH, Cai B, Tuo Y, Wang J, Zang ZJ, Tu X, Gao Y, Su Z, Li W, Li G, et al: Characterization of Nestin-positive stem Leydig cells as a potential source for the treatment of testicular Leydig cell dysfunction. Cell Res 24: 1466-1485, 2014.

26. Wang H, Wang Q, Zhao XF, Liu P, Meng XH, Yu T, Ji YL, Zhang $\mathrm{H}$, Zhang $\mathrm{C}$, Zhang $\mathrm{Y}$ and $\mathrm{Xu} \mathrm{DX}$ : Cypermethrin exposure during puberty disrupts testosterone synthesis via downregulating StAR in mouse testes. Arch Toxicol 84: 53-61, 2010.

27. Caron KM, Soo SC, Wetsel WC, Stocco DM, Clark BJ and Parker KL: Targeted disruption of the mouse gene encoding steroidogenic acute regulatory protein provides insights into congenital lipoid adrenal hyperplasia. Proc Natl Acad Sci USA 94: 11540-11545, 1997

28. King SR, Manna PR, Ishii T, Syapin PJ, Ginsberg SD, Wilson K, Walsh LP, Parker KL, Stocco DM, Smith RG and Lamb DJ: An essential component in steroid synthesis, the steroidogenic acute regulatory protein, is expressed in discrete regions of the brain. J Neurosci 22: 10613-10620, 2002.

29. Stocco DM and Clark BJ: The role of the steroidogenic acute regulatory protein in steroidogenesis. Steroids 62: 29-36, 1997.

30. Raucci F, D'Aniello A and Di Fiore MM: Stimulation of androgen production by D-aspartate through the enhancement of StAR, P450scc and 3 $\beta$-HSD mRNA levels in vivo rat testis and in culture of immature rat Leydig cells. Steroids 84: 103-110, 2014.

31. Stocco DM: StAR protein and the regulation of steroid hormone biosynthesis. Annu Rev Physiol 63: 193-213, 2001.

32. Hu Y, Dong C, Chen M, Lu J, Han X, Qiu L, Chen Y, Qin J, Li X, Gu A, et al: Low-dose monobutyl phthalate stimulates steroidogenesis through steroidogenic acute regulatory protein regulated by SF-1, GATA-4 and C/EBP-beta in mouse Leydig tumor cells. Reprod Biol Endocrinol 11: 72, 2013.
33. Pakarinen P, Vihko KK, Voutilainen $\mathrm{R}$ and Huhtaniemi $\mathrm{I}$ Differential response of luteinizing hormone receptor and steroidogenic enzyme gene expression to human chorionic gonadotropin stimulation in the neonatal and adult rat testis. Endocrinology 127: 2469-2474, 1990.

34. Baba Y: Effect of HCG administration in the gossypol-treated male rats. Hinyokika Kiyo 34: 643-647, 1988 (In Japanese).

35. Scott IS, Charlton HM, Cox BS, Grocock CA, Sheffield JW and O'Shaughnessy PJ: Effect of LH injections on testicular steroidogenesis, cholesterol side-chain cleavage P450 mRNA content and Leydig cell morphology in hypogonadal mice. J Endocrinol 125: 131-138, 1990.

36. Xu Z, Kawai M, Bandiera SM and Chang TK: Influence of dietary zinc deficiency during development on hepatic CYP2C11, CYP2C12, CYP3A2, CYP3A9, and CYP3A18 expression in postpubertal male rats. Biochem Pharmacol 62: 1283-1291, 2001.

37. Croxford TP, McCormick NH and Kelleher SL: Moderate zinc deficiency reduces testicular Zip6 and Zip10 abundance and impairs spermatogenesis in mice. J Nutr 141: 359-365, 2011.

38. Favier AE: The role of zinc in reproduction. Hormonal mechanisms. Biol Trace Elem Res 32: 363-382, 1992.

39. Om AS and Chung KW: Dietary zinc deficiency alters 5 alphareduction and aromatization of testosterone and androgen and estrogen receptors in rat liver. J Nutr 126: 842-848, 1996.

40. Qureshi IZ and Abbas Q: Modulation of testicular and whole blood trace element concentrations in conjunction with testosterone release following kisspeptin administration in male rabbits (Oryctolagus cuniculus). Biol Trace Elem Res 154: 210-216, 2013.

41. Sunderman FW Jr: The influence of zinc on apoptosis. Ann Clin Lab Sci 25: 134-142, 1995.

42. Vallee BL and Falchuk KH: The biochemical basis of zinc physiology. Physiol Rev 73: 79-118, 1993.

43. Prasad AS: Clinical and biochemical manifestation zinc deficiency in human subjects. J Pharmacol 16: 344-352, 1985.

44. Root AW, Duckett G, Sweetland M and Reiter EO: Effects of zinc deficiency upon pituitary function in sexually mature and immature male rats. J Nutr 109: 958-964, 1979.

45. Huang L and Tepaamorndech S: The SLC30 family of zinc transporters - a review of current understanding of their biological and pathophysiological roles. Mol Aspects Med 34: 548-560, 2013.

46. Kelleher SL, Seo YA and Lopez V: Mammary gland zinc metabolism: regulation and dysregulation. Genes Nutr 4: 83-94, 2009.

47. Chi ZH, Feng WY, Gao HL, Zheng W, Huang L and Wang ZY: ZNT7 and $\mathrm{Zn}^{2+}$ are present in different cell populations in the mouse testis. Histol Histopathol 24: 25-30, 2009.

48. Chi ZH, Ren H, Wang X, Rong M, Huang L and Wang ZY: The cellular and subcellular localization of zinc transporter 7 in the mouse spinal cord. Histol Histopathol 23: 781-787, 2008.

49. Huang L, Yan M and Kirschke CP: Over-expression of ZnT7 increases insulin synthesis and secretion in pancreatic beta-cells by promoting insulin gene transcription. Exp Cell Res 316: 2630-2643, 2010 .

50. Mukherjee S, Chiu R, Leung SM and Shields D: Fragmentation of the Golgi apparatus: an early apoptotic event independent of the cytoskeleton. Traffic 8: 369-378, 2007.

51. Chi ZH, Wang X, Wang ZY, Gao HL, Dahlstrom A and Huang L: Zinc transporter 7 is located in the cis-Golgi apparatus of mouse choroid epithelial cells. Neuroreport 17: 1807-1811, 2006. 